\title{
A VISÃO DA FAMÍLIA SOBRE O TRABALHO DE PROFISSIONAIS DE SAÚDE MENTAL DE UM CENTRO DE ATENÇÃO PSICOSSOCIAL
}

\author{
The vision from the family about the work of the mental health \\ professionals in a Psychosocial Care Center
}

\section{La visión de la familia sobre el trabajo de los profesionales de la salud mental en un Centro de Atención Psico-social}

\section{RESUMO}

0 objetivo foi compreender a visão de familiares de usuários de um Centro de Atenção Psicossocial (CAPS) em relação ao trabalho da equipe de saúde mental. Trata-se de uma pesquisa de abordagem qualitativa do tipo fenomenológico, com a utilização do referencial da sociologia fenomenológica de Alfred Schütz. Os dados foram coletados por meio de entrevista realizada com 13 familiares de usuários de um CAPS em 2006. A análise compreensiva permitiu considerar que os familiares se sentem, diante das ações da equipe, reconhecidos por esta em sua situação biográfica, embora este reconhecimento não seja pleno. Além disso, a gestão das políticas de saúde mental municipal tem refletido negativamente no cotidiano de trabalho da equipe. Conhecer e compreender a biografia da família e reconhecê-la como uma parceira imprescindível à equipe de saúde mental pode servir como uma potente estratégia de atenção em saúde mental, contribuindo para a consolidação de políticas públicas em saúde mental.

Palavras-chave: Saúde Mental. Serviços de Saúde Mental. Família. Filosofia.

\begin{abstract}
This study aimed in understanding the vision from the family members of a Psychosocial Attention Center' (CAPS) users about the work of the mental health professionals. It's a qualitative research, based on Alfred Schutz' Social Phenomenology framework. Data were collected through interviews with 13 family members in 2006 at a CAPS unit in Porto Alegre. The comprehensive analysis allowed considering that the family members don't feel fully recognized in their life experience about the team's actions. Moreover, the management of municipal policies on mental health has reflected negatively in the daily work of the team. To know and to understand the biography of the family is indispensable to the CAPS team work. Recognizing the family as a partner can be an important strategy to the team work, contributing to the consolidation of public policies on mental health.
\end{abstract}

Keywords: Mental Health. Mental Health Services. Family. Philosophy

\section{Resumen}

El objetivo fue comprender la visión que tienen los familiares de pacientes de un Centro de Atención Psico-social (CAPS) sobre el trabajo del equipo de salud mental. Se trata de una investigación cualitativa, con fundamentación en el referencial teórico-metodológico de la fenomenología social de Alfred Schutz. Los datos fueron recolectados por medio de entrevistas con 13 familiares en un CAPS localizado en Porto Alegre. El análisis comprensivo permitió considerar que la familia no se siente reconocida en su biografía en relación con el trabajo del equipo. Además, la gestión de las políticas municipales en materia de salud mental se ha reflejado negativamente en el trabajo diario del equipo. Conocer y comprender la biografía de la familia es esencial para el trabajo del equipo de un CAPS. Reconocer a la familia como un socio indispensable puede ser una estrategia importante para el equipo, porque puede contribuir a la consolidación de las políticas públicas sobre salud mental.

Palabras-clave: Salud Mental. Servicios de Salud Mental. Familia. Filosofía

'Doutorando em Enfermagem e Bolsista REUNI do Programa de Pós-Graduação em Enfermagem da Escola de Enfermagem da Universidade Federal do Rio Grande do Sul (PPGENF/ EEUFRGS). Brasil. E-mail: mcamatta@gmail.com, ${ }^{2}$ Doutor em Enfermagem. Docente do Departamento de Assistência e Orientação Profissional e do (PPGENF/ EEUFRGS). Brasil. E-mail: jaco_schneider@uol.com.br 


\section{INTRODUCÃO}

No Brasil, as mudanças mais significativas na legislação em saúde mental ocorreram juntamente com a redemocratização do país, impulsionadas, por um lado, pelo movimento da reforma sanitária e, por outro, pelo Movimento dos Trabalhadores em Saúde Mental, fortemente influenciados pela sociedade civil organizada. Essas mudanças estavam pautadas na tentativa de superação do modo asilar, ainda hegemônico na organização da assistência em saúde mental.

Neste modo, o indivíduo é visto como doente e não atua no seu tratamento, sendo isolado do convívio familiar e social, assistido por uma equipe multiprofissional por meio de intervenções focadas, e o hospital psiquiátrico é o principal local de tratamento. Já no modo psicossocial, preconizado pela reforma psiquiátrica, o indivíduo é considerado como uma pessoa em sofrimento psíquico, que, juntamente com seus familiares e o meio social em que vivem, se torna fundamental no tratamento. Nesse modo, os sujeitos são assistidos por uma equipe multiprofissional que procura trabalhar de forma interdisciplinar em locais de tratamento diversificados, tendo em vista a reabilitação psicossocial e a reintegração sociocultural dos sujeitos em sofrimento psíquico'.

0 confrontamento entre esses paradigmas nos permite dizer que as ações das equipes de saúde mental, no modo psicossocial, devem estar focadas não mais na doença, mas no sofrimento existencial do sujeito e na sua relação com o corpo social. Esta mudança epistemológica implica que o meio social do indivíduo deva ser considerado no trabalho da equipe de saúde mental, sobretudo da família, buscando sua inserção e envolvimento no tratamento do usuário.

Por quase dois séculos, a família foi afastada do tratamento oferecido, pois a sua inserção no tratamento do sujeito em sofrimento psíquico foi negada devido ao entendimento de que ela poderia prejudicar o processo de cura ${ }^{2}$. Esta situação perdurou desde Philippe Pinel, o principal representante e fundador da psiquiatria como especialidade médica, até as experiências de reforma psiquiátrica ocorridas em meados do século XX. Assim, nas décadas de 1950 e 1960, a família voltou a compor o cenário da assistência, graças à proposta de desinstitucionalização dos indivíduos alocados em hospitais psiquiátricos ocorrida em vários países².

A desinstitucionalização apresenta como característica não a "desospitalização" ou a "desassistência", mas a crítica epistemológica ao saber médico constituinte da psiquiatria, na busca do resgate dos direitos dos cidadãos 3 .

No Brasil, a participação da família no tratamento está prevista nas novas legislações no campo da saúde mental, dentre as quais destacamos a Portaria $n^{\circ}$ 224/1992, do Ministério da Saúde, que dispõe sobre as diretrizes assistenciais em saúde mental e estabelece normas para 0 atendimento ambulatorial e hospitalar ${ }^{4}$. Posteriormente, esta portaria foi atualizada pela de número 336/2002, a qual redefiniu parâmetros para 0 atendimento ambulatorial, diversificando as modalidades de serviços substitutivos de atenção diária 5 .

Nesse sentido, as políticas de saúde mental vigentes vêm desde a década de 1990 estimulando a constituição de uma rede de saúde mental nos estados e municípios com a implantação de serviços substitutivos ao hospital psiquiátrico.

Com essas portarias, a atenção em saúde mental deveria ser conduzida em diversos tipos de serviços, tais como os hospitais-dia, leitos ou unidades psiquiátricas e serviços de emergências psiquiátricas em hospitais gerais, serviços da atenção básica como unidades básicas de saúde e as de saúde da família, e os Centros de Atenção Psicossocial (CAPS). Contudo, estes últimos foram escolhidos pelo Ministério da Saúde como 0 articulador da rede de saúde mental ${ }^{5}$.

Vale destacar que os CAPS foram definidos por ordem crescente de porte/complexidade e abrangência populacional, constituindo-se em CAPS I, CAPS II e CAPS III, CAPS i II (infância e adolescência) e CAPS ad II (álcool e outras drogas). Além disso, esses serviços preconizam o atendimento prioritário de pessoas em sofrimento psíquico severo e persistente na área territorial dos respectivos serviços ${ }^{5}$.

Observamos que, por meio desta e de outras modalidades de atendimento propostas, estimulou-se 0 atendimento das pessoas em sofrimento psíquico o mais próximo da sua residência, em serviços funcionando em regime de "portas abertas" na comunidade. Desta maneira, a equipe de saúde mental deveria conduzir suas ações terapêuticas para a promoção da reabilitação psicossocial dessas pessoas, sem romper os laços sociais entre elas e suas famílias e a comunidade.

É importante destacar, ainda, que a equipe de saúde mental, de todos os serviços públicos de saúde mental propostos pelas portarias citadas anteriormente, deveria se ocupar também em assistir às famílias dos usuários dos serviços. Contudo, vale destacar que a relação entre profissionais de saúde mental e os sujeitos em sofrimento psíquico e seus familiares foi historicamente construída por meio de uma relação de distanciamento.

$\mathrm{Na}$ tentativa de sanar tal ruptura, surge com o modo psicossocial a possibilidade de implementação de um novo modelo fundamentado na relação de respeito, solidariedade e cidadania. Assim, observamos que as legislações no campo da saúde mental têm se preocupado cada vez mais, não só com a assistência do sujeito em sofrimento psíquico, mas também de sua família, levando a equipe de saúde mental em considerar esta dimensão do seu trabalho nos diferentes tipos de serviços de atenção em saúde mental.

Tendo em vista que as propostas da reforma psiquiátrica estão pautadas no modo psicossocial e que o processo de mudança paradigmática desencadeado pela adoção desta postura tem levado a crises e mudanças no campo da saúde mental, com esta investigação, buscamos compreender a visão da família sobre o trabalho da equipe de profissionais de saúde mental de um CAPS II. 
Esperamos que esta investigação possa subsidiar a reflexão das equipes de saúde mental sobre o seu trabalho, possibilitando uma maior compreensão do movimento atual da mudança paradigmática na atenção em saúde mental e as repercussões no cotidiano das equipes.

\section{REFERENCIAL TEÓRICO-FILOSÓFICO}

Neste estudo, utilizamos como referencial teórico-filosófico a sociologia fenomenológica de Alfred Schütz, o qual nos propiciou 0 aprofundamento do conhecimento de algumas dimensões da realidade social de familiares de usuários de um CAPS acerca do trabalho da equipe de saúde mental. Neste referencial, enquanto um grupo social, os familiares são compreendidos pelo pesquisador, a partir das suas experiências singulares vividas e dos significados atribuídos a elas ${ }^{6}$.

Essas experiências não ocorrem isoladamente, mas no contexto do mundo social, o qual é compartilhado, vivenciado e interpretado pelo sujeito e seus semelhantes. Desta maneira, é possivel compreender o mundo com os outros em seu significado intersubjetivo, isto é, a partir das relações sociais ${ }^{6}$.

Neste artigo, para a compreensão das descrições dos familiares acerca do fenômeno - trabalho da equipe de profissionais de saúde mental do CAPS - utilizamos os conceitos de interesse à mão, sistemas de relevâncias (intrínsecos e impostos), situação biográfica determinada e estoque de conhecimento à mão da sociologia fenomenológica ${ }^{6}$.

0 projetar e o agir social são possíveis ao sujeito do mundo social, a partir do interesse à mão, o qual representa um interesse prioritário dentro de um sistema maior que levará a uma ação. Neste referencial, o interesse à mão é moldado pelo sistema de relevâncias e o estoque de conhecimento à mão, 0 que motivará o sujeito a desempenhar um determinado comportamento social?.

0 sistema de relevância intrínseco diz respeito aos próprios interesses; já o sistema de relevância imposto diz respeito aos interesses de outros. Nesta situação, para Schütz, quando um sujeito se volta espontaneamente para outro, emergem desta relação as relevâncias intrínsecas em comum; contudo, alerta que uma parte do sistema de relevâncias intrínsecas de cada um permanecerá não compartilhada ${ }^{6}$.

Por sua vez, o estoque de conhecimento à mão refere-se ao estoque de conhecimento do sujeito adquirido ao longo de sua vida (biografia), por meio das suas experiências vividas no mundo social. Trata-se da situação biográfica determinada do sujeito, que representa a sedimentação das suas experiências ao longo do tempo, que funciona como um esquema de referência para interpretação do mundo social. .

Então, o interesse à mão do sujeito motiva o seu pensar, projetar e agir, e estabelece os problemas a serem solucionados pelo pensamento e os objetivos a serem atingidos por suas ações ${ }^{7}$. Assim, as ações do sujeito social emergem das relações intersubjetivas estabelecidas no mundo social, considerando seus interesses e os de outros, e a sua situação biográfica.

\section{METODOLOGIA}

Este é um estudo de abordagem qualitativa, do tipo fenomenológico, o qual visa desvelar a experiência vivida dos sujeitos, experienciada como fenômeno. Apoiamo-nos no referencial da sociologia fenomenológica de Alfred Schütz para a condução deste estudo.

0 campo de estudo foi um CAPS II localizado em Porto Alegre. A equipe de saúde mental deste serviço é composta por três psiquiatras, duas enfermeiras, quatro auxiliares de enfermagem, três terapeutas ocupacionais, três psicólogas, uma assistente social, uma educadora física e uma nutricionista.

Foram pesquisados 13 familiares de usuários do serviço que estivessem mais envolvidos com o tratamento do familiarusuário, os quais foram identificados por meio de conversas informais com usuários, familiares e a própria equipe. Além disso, os selecionados deveriam ter disponibilidade em participar do estudo.

Para a coleta das informações, foram realizadas entrevistas nos meses de outubro e novembro de 2006. Utilizamos a seguinte questão norteadora: "Como você visualiza o trabalho da equipe do CAPS". As entrevistas foram encerradas quando observamos a repetição acentuada das mesmas afirmações.

Antes da entrevista, os sujeitos foram informados sobre a garantia de sigilo e confidencialidade quanto às informações prestadas, e ainda tiveram assegurados o direito de serem esclarecidos ou de abandonarem a pesquisa em qualquer etapa do processo, sem danos à sua integridade. Assim, tanto os pesquisadores quanto os sujeitos participantes deste estudo assinaram o Termo de Consentimento Livre e Esclarecido em duas vias, ficando uma cópia para os sujeitos do estudo.

Esta pesquisa cumpriu as exigências legais e éticas, sendo aprovada pelo Comitê de Ética em Pesquisa da Secretaria Municipal de Saúde de Porto Alegre, sob número de parecer 001.042261.06.6 em 26 de outubro de 2006.

As informações foram analisadas de acordo com as convergências das unidades de significado que emergiram dos depoimentos à luz do referencial da sociologia fenomenológica de Alfred Schütz. Para o desvelamento da essência do fenômeno, seguimos os seguintes passos: leitura dos depoimentos; releitura dos depoimentos destacando unidades de significado; mediante uma postura reflexiva, descrevemos o que estava expresso nestas afirmações; a partir do estabelecimento das convergências das unidades de significado, construímos categorias concretas; buscamos uma compreensão vaga e mediana dos depoimentos a partir das categorias concretas; $\mathrm{e}$, por fim, a interpretação compreensiva para desvelar a essência do fenômeno.

A análise das informações nos permitiu organizar os resultados das experiências vividas pelos familiares em três categorias concretas, sendo suas denominações inspiradas em conceitos do referencial da sociologia fenomenológica. Assim, o trabalho da equipe do CAPS é vivenciado pelos familiares de 
acordo com as seguintes categorias: o trabalho fundamentado no interesse à mão; o trabalho como projeto, ação e ato; e o trabalho permeado por relações interativas.

Neste artigo apresentamos a interpretação compreensiva dos depoimentos da categoria concreta - o trabalho da equipe fundamentado no interesse à mão. A interpretação compreensiva, à luz da sociologia fenomenológica, nos permitiu realizar um movimento de voltar às coisas mesmas, desvelando algumas facetas do saber imanente dos familiares.

$\mathrm{Na}$ apresentação dos depoimentos, os familiares estão representados pela letra $F$, seguida do número correspondente à ordem com que as entrevistas foram realizadas, e, para garantir o anonimato, utilizamos nomes fictícios para os usuários e profissionais.

\section{RESULTADO E DISCUSSÃO}

As descrições singulares de cada familiar entrevistado acerca do fenômeno em estudo permitiram-nos delimitar a categoria "o trabalho da equipe fundamentado no interesse à mão", considerando que, de acordo com o referencial da sociologia fenomenológica, a situação biográfica dos pesquisadores e dos pesquisados interferem nesta construção. Assim, esta construção emergiu da história, da cultura e das relações sociais dos sujeitos envolvidos ${ }^{6}$.

Enquanto grupo social, os familiares expressaram as experiências vividas sobre 0 trabalho da equipe do CAPS, a partir do lugar que eles ocupam no mundo social. Assim, o interesse à mão do sujeito social é um interesse eminentemente prático, pois surge do seu cotidiano $0^{6}$. Trata-se, portanto, de um interesse prioritário dentro de um sistema maior de interesses inter-relacionados, que determinará o que será pensado e projetado e que levará a uma ação.

Este sistema de interesse não é homogêneo, pois pode mudar de acordo com o papel desempenhado pelo ator social em diferentes âmbitos do mundo social, e nem constante, porque pode adquirir maior ou menor prioridade entre 0 agora e 0 agora que acabou de passar?.

Assim, o trabalho da equipe do CAPS é devido a um interesse que motiva o pensar, o projetar e o agir desta equipe como atores sociais. Isso é observado nos depoimentos dos familiares, que revelam o trabalho da equipe fundamentado em um interesse em relação à atenção em saúde mental ao familiarusuário, e também o envolvimento dos familiares neste processo.

0 interesse de todos, assistente social, psicólogo, enfermeiro, todos aqui [...]. (F1)

A gente acha que está bem atendido em tudo no que a gente precisou e no que está precisando. (F3)

Eu fui poucas vezes lá, mas nestas poucas vezes, eu até fiquei emocionada, emotiva, porque eu vi que elas se preocupavam comigo também. (F6)
Ao se sentirem acolhidos em seu sofrimento, os familiares parecem conferir 0 trabalho com as famílias dedicado pela equipe do CAPS, como parte do interesse desta equipe na atenção em saúde mental, pois isso envolve o atendimento das necessidades tanto dos usuários quanto da sua família.

Assim, na atenção em saúde mental desenvolvida pela equipe do CAPS, as necessidades da família devem ser contempladas pelas ações da equipe, configurando-se em um dos objetos de trabalho da equipe. 0 Ministério da Saúde prevê que os CAPS devem atender, além dos sujeitos em sofrimento psíquico, a sua família, procurando envolvê-la e inseri-la na dinâmica do serviço ${ }^{5}$.

Contudo, desenvolver estratégias de cuidados mais apropriadas às necessidades das famílias implica conhecê-las em suas múltiplas dimensões existenciais, por meio de uma maior aproximação do seu cotidiano e da captação dos sentidos que emergem de suas histórias de vida? .

No pensamento de Schütz, o interesse à mão está alicerçado em dois pontos fundamentais: 0 estoque de conhecimento à mão e o sistema de relevâncias dos atores sociais ${ }^{6}$. Em seguida articulamos esses conceitos com o material empírico deste estudo.

0 estoque de conhecimento à mão serve como código de referência para subsidiar as interpretaç̃oes das experiências passadas e do presente do ator social, determinando também as antecipações futuras deste ator ${ }^{7}$. 0 estoque de conhecimento à mão do familiar está dado pela sua situação biográfica determinada, que é única para cada um, pois se refere à sua história e à sedimentação de todas as experiências vividas anteriores junto ao sujeito em sofrimento psíquico ${ }^{10}$.

Assim, quanto à situação biográfica determinada dos familiares, embora estes se sintam reconhecidos pela equipe pela sua história junto ao familiar-usuário, nos depoimentos também foi evidenciado que nem sempre esta situação biográfica determinada é plenamente reconhecida pela equipe do CAPS.

[...] eu consegui, mas com muita luta lá, e aí então ele [médico] trocou o remédio. [...] eu já vinha com muitos anos, já sabia do problema dele, porque a mãe já sabe do problema. Então, eu tinha que internar ele. Aí eles falaram, o remédio é baixo, tinha que ter aumentado a dose. [...] De tão desesperada, ligava e falava com eles e tudo, mas eles não me escutaram. (F5)

É compreensível que a família frequentemente resista à nova proposta de tratamento pautada na desinstitucionalização e exija mais dos serviços e das equipes de saúde mental, pois, em algumas situações, sente-se desamparada na responsabilidade de cuidar ${ }^{11}$. Então, há momentos em que as solicitações desses familiares não são atendidas pela equipe, 0 que gera sentimento de frustração dos mesmos diante do seu trabalho. 
Há situações, ainda, em que as expectativas de familiares acerca do trabalho da equipe do CAPS vão além dos objetivos deste serviço, pois esperam que a equipe resolva os problemas referentes ao desemprego e a distribuição de renda ${ }^{12}$.

Por outro lado, os familiares apontam que a equipe flexibiliza o agendamento de consultas do usuário no serviço por reconhecer o desgaste destes no convívio na família. Entretanto, em algumas ocasiões, este desgaste familiar reflete no trabalho da equipe, pois as orientações e prescrições realizadas pelos profissionais do CAPS nem sempre são cumpridas pelos familiares. Essas observações estão ilustradas a seguir:

A vantagem que tem aqui é que o doutor José, que trata dele, quando eu não posso trazer o Ernesto, venho sozinha, aí ele marca a próxima consulta [...] aí, já duas vezes que eu venho e não trago o Ernesto, porque eu vindo sozinha é uma coisa, eu trazer ele é outra. [...] Eu mesma precisava fazer um tratamento. Eu mesma já disse para o doutor José: doutor, eu não tenho mais condições de [...] às vezes o doutor José é meio [...] fica meio descontente comigo, mas eu digo: doutor, eu estou esquecida. (F11)

0 reconhecimento do desgaste vivenciado pela família leva a equipe a romper com regras da organização do serviço, flexibilizando horários e a forma de atendimento do usuário. Moldar-se às necessidades dos usuários e de suas famílias é uma importante estratégia de vinculação e corresponsabilização entre familiares e equipe.

Neste depoimento fica evidenciado que o desgaste da equipe também ocorre quando o familiar se refere ao "descontentamento do doutor" com ele. 0 trabalho no CAPS gera diferentes sentimentos nos membros da equipe, levando alguns deles ao comprometimento de sua saúde mental ${ }^{13}$.

Nesse sentido, a promoção da saúde mental deve ser exercitada continuamente no cotidiano dos CAPS, e estar voltada não apenas para os usuários e familiares, mas também para a equipe. Assim, a busca de humanização no atendimento do sujeito em sofrimento psíquico deve considerar o humano que cuida - o trabalhador do CAPS'13.

Em outras situações, os familiares consideraram que as informações fornecidas pela equipe em relação ao tratamento do familiar-usuário eram insuficientes e inespecíficas.

Quando eu vim para cá, eu não tinha nada, não sabia nada dessas coisas todas. Eu tive conhecimento até dos sintomas que poderia levar. Eu me informava aqui fora com as pessoas, numa fila do SUS, numa fila de uma farmácia [...] Mas eu, enquanto familiar, achei respostas na rua. Eeu acho que para melhorar esse campo no CAPS, deveria ter uma parte com os parentes. De explicar: o seu familiar está passando por isto; ele vai ter crises assim. Eu acho que precisava disto. Isso ficou muito vago aqui. (F10)

Essa constatação é relevante ao ponderarmos que as informações solicitadas pelos familiares deveriam considerar as especificidades da situação biográfica determinada de cada família, pois o que vem sendo informado nos encontros entre os profissionais e a família não tem atendido aos anseios dos familiares. Desta maneira, os familiares pedem uma relação de troca mais intensa com a equipe, pois o seu conhecimento sobre o sofrimento psíquico vem se construindo junto a pessoas externas ao serviço.

Embora seja importante a implementação de um plano de informação e orientação realizado pelo profissional de saúde mental junto aos familiares, estes necessitam de informações personalizadas, cujo conteúdo esteja voltado para o seu familiar específico, e não para um indivíduo portador de algum transtorno ${ }^{8}$.

Permitir às famílias um espaço para verbalizar sentimentos, angústias, impressões, medos, verdades e dúvidas, acerca do familiar em sofrimento psíquico e de seus próprios sofrimentos, torna-se momento oportuno para a equipe aproximar-se do mundo cotidiano dessas pessoas. Isso possibilitaria uma melhor compreensão dos sentidos atribuídos por eles na assistência ao seu familiar-usuário8.

Conforme os depoimentos dos familiares, a equipe do CAPS deveria considerar a sua situação biográfica determinada: a situação de ser um familiar, membro de uma família que convive com um usuário que está em sofrimento psíquico; biográfica, no sentido de ter uma experiência vivida, história de vida, marcada pelo convívio com a loucura; e determinada, como uma situação que está em constante transformação.

0 desgaste familiar representa uma maneira de esta situação biográfica se mostrar como um aspecto que deva ser considerado pela equipe em seu trabalho. Por outro lado, é importante que a equipe crie estratégias para equacionar o seu sofrimento no trabalho, minimizando o seu desgaste em lidar com o usuário em sofrimento psíquico e sua família.

No pensamento de Schütz, a situação biográfica determinada e o estoque de conhecimento à mão dos familiares de usuário do CAPS compõem, juntamente com os seus sistemas de relevâncias, os elementos que vão subsidiar o pensamento, a ação e a interpretação desses atores sociais, configurados no interesse à mão.

Uma vez estabelecido este interesse à mão, 0 ator social determinará o sistema de relevâncias intrínsecas com relação ao interesse escolhido, ficando até certa medida sob o seu controle. Por outro lado, a constituição final do interesse à mão sofre interferência de eventos externos ao ator, caracterizados como interesses impostos.

Assim, neste estudo, os familiares consideraram que 0 trabalho da equipe do CAPS sofre interferência da gestão das 
políticas públicas. Esta interferência é esperada, pois, o CAPS é um serviço público de saúde; contudo, em Schütz, a interferência da gestão das políticas públicas pode ser interpretada como uma imposição de um sistema de relevância, na qual outros interesses confrontam os interesses intrínsecos dos profissionais.

0 prefeito, eu acho que deixa alguma coisa a desejar, quer dizer, muita coisa. Na saúde eu acho que ele deixou muito, porque isto aqui era muito melhor, em tudo. Era melhor na saúde, barbaridade. (F1)

Tinham farmácia, não tem mais. Uma série de coisas, que foi cortada verba [...] Então, o serviço perdeu em coisa. (F4)

Nos depoimentos dos familiares, emergiram que os interesses impostos às ações da equipe são vivenciados como provenientes, fundamentalmente, da gestão das políticas públicas em saúde, demonstrando um caráter marcadamente político nos depoimentos, como um interesse imposto. Os reflexos deste interesse imposto vêm se mostrando aos familiares, sobretudo, na ingerência das políticas públicas em saúde e de saúde mental, ilustrando tal consideração quando se referem ao sucateamento do serviço e ao corte de recursos financeiros.

Aliadas à falta de condições de trabalho e à dificuldade em manter projetos de trabalho no serviço, a equipe de CAPS também sofre as consequências dessa forma de condução das políticas públicas de saúde, gerando, consequentemente, insegurança ${ }^{10}$.

Além do sucateamento do serviço de saúde mental e o corte de recursos financeiros, os familiares relataram a insuficiência do número de serviços de saúde mental, destacando que serviços semelhantes ao CAPS deveriam existir em vários bairros da cidade, para assim permitir o acesso àqueles que precisam deste tipo de serviço.

Uma amiga nossa nos indicou o CAPS. Eu acho que existe uma boa relação. Acho até que deveria ter mais, porque a psiquiatria, em termos de SUS, ela é muito difícil. (F1)

Até nem sabia que existia o CAPS; que existia este tipo de serviço. Se tivesse mais, pelos vários bairros, seria muito bom porque têm muitas pessoas que tem problemas psicológicos, e por falta de lugares para serem atendidas, cada vez vão piorando mais os casos. (F8)

Desta maneira, com a ampliação do número de serviços, os familiares relatam que muitos problemas enfrentados pelas pessoas em sofrimento psíquico e suas famílias poderiam ser prevenidos ou mesmo minimizados.

A carência de respostas do governo municipal às políticas públicas compromete a construção de uma assistência em saúde mental que venha efetivamente substituir o modelo tradicional ${ }^{15}$. Esta carência está evidenciada no desinteresse e descompromisso de gestores na implementação das políticas de saúde mental, na insuficiência do número de serviços de saúde mental e no sucateamento dos existentes.

Os CAPS são serviços potencialmente inovadores e criativos no âmbito da atenção em saúde mental. Entretanto, as garantias jurídico-administrativas para que os CAPS fossem implantados em todo território nacional mobilizaram os gestores municipais para a criação de serviços extrahospitalares em saúde mental, eminentemente na modalidade de CAPS ${ }^{16}$. Isto fez com que os gestores buscassem organizar a rede de atenção em saúde mental a partir desses serviços, tendo em vista o financiamento atrelado a sua implantação e funcionamento.

0 que se evidencia nos depoimentos dos familiares é 0 relato acerca da insuficiência de serviços de saúde, especificamente de saúde mental, para compor uma rede que faça frente às necessidades das pessoas. Diante disso, observamos que os familiares entendem a promoção de saúde mental ainda restrita aos serviços de saúde mental.

Apesar de os CAPS terem sido escolhidos pelo Ministério da Saúde como articuladores da rede de saúde mental, entendemos que a atenção em saúde mental não deve ficar restrita a esses serviços, mas ao contrário, ser conduzida em uma rede diversificada de serviços e de espaços sociais na comunidade.

Esses espaços sociais remetem-nos à noção de um trabalho desenvolvido no e com o território. Isto significa que a equipe deva considerar tanto a região geográfica quanto o espaço formado pelas pessoas que nela habitam, os seus conflitos, interesses, amigos, vizinhos, família, instituições e cenários. Com esta noção de território, será possível organizar uma rede de atenção às pessoas em sofrimento psíquico e suas famílias, amigos e outros implicados 5 .

Contudo, diante da relevância atribuída aos CAPS pelos familiares, consideramos que a abertura deste serviço precisa ser garantida por meio de sua inserção no território, tornando cada vez mais imprecisos os limites do que é dentro e do que é fora ${ }^{17}$. A promoção da saúde mental deve ocorrer de dentro para fora dos serviços, explorando as possibilidades do território e evitando o reducionismo da atenção em saúde mental em serviços de saúde como os CAPS.

Embora os familiares reconheçam algumas dificuldades enfrentadas pela equipe do CAPS em seu cotidiano, consideram o trabalho da equipe importante, não só para os sujeitos em sofrimento psíquico, mas também para a sociedade como um todo, sobretudo para as famílias que convivem cotidianamente com esses sujeitos. Além disso, ressaltaram que a equipe deve se orgulhar do trabalho desenvolvido.

[...] percebe-se que isto é muito importante para as pessoas que precisam deste atendimento, como 
para a sociedade em geral [...] a convivência com a familia fica praticamente impossível, extremamente difícil [...] é uma coisa muito necessária. (F9)

Agradeço que tenha este lugar pelo SUS (Sistema Único de Saúde). [...] Então, tem este lugar que ainda tem pessoas que podem falar de cabeça erguida: viva o SUS. Viva as pessoas que trabalham lá. O trabalho que eles põem lá para os pacientes. (F6)

Uma expectativa marcante da família quanto ao trabalho da equipe de CAPS é a resolução de problemas referentes à sobrecarga gerada pelo convívio com o familiar em sofrimento psíquico $^{12}$. Este aspecto deve ser considerado pela equipe na medida em que interfere diretamente no alcance das propostas da reforma psiquiátrica, dentre as quais destacamos a desinstitucionalização.

Além disso, como identificado no outro estudo ${ }^{12}$, observamos que os familiares dos usuários do CAPS destacam a importância da inclusão da família e da sociedade no tratamento e na manutenção da liberdade do usuário.

De acordo com o referencial da sociologia fenomenológica, apesar de parecerem como de um interesse imposto, e de caráter negativo, as políticas públicas em saúde mental mostraram-se para os familiares com seus aspectos positivos, na medida em que o serviço do CAPS se caracteriza como um serviço de saúde público, do Sistema Único de Saúde.

0 trabalho da equipe do CAPS é caracterizado pelos familiares como um interesse à mão da equipe, moldado por um sistema de interesses diversificados (intrínsecos e impostos) e pela situação biográfica, principalmente da equipe. Contudo, os familiares consideram os CAPS como serviços de atenção em saúde mental de importante relevância social.

\section{CONSIDERACÕES FINAIS}

Os familiares descreveram que o trabalho da equipe está pautado em um interesse genuíno em assistir ao usuário do CAPS e sua família. No entanto, os familiares não se sentem reconhecidos plenamente em sua situação biográfica determinada diante das ações da equipe.

Conhecer e compreender a biografia da família, e dos familiares do sujeito em sofrimento psíquico pode servir como uma potente estratégia da equipe do CAPS na atenção à saúde mental. Estar junto às famílias pode potencializar 0 enfrentamento das adversidades impostas às mesmas em seu cotidiano, possibilitando-as "escrever" sua biografia de maneira menos dolorosa e sofrida.

Foi evidenciado que a gestão das políticas de saúde mental municipal reflete diretamente no cotidiano do trabalho da equipe de saúde mental junto aos usuários e seus familiares. Estes sentem as interferências, sobretudo, na insuficiência do número de serviços de saúde mental de administração pública no município e no sucateamento dos serviços existentes. A falta de uma rede de atenção em saúde mental devidamente constituída no município prejudica sobremaneira o desempenho do trabalho da equipe do CAPS, comprometendo os resultados da atenção psicossocial deste serviço.

Pensamos que os profissionais de saúde mental, juntamente com usuários e familiares, são importantes protagonistas no processo de transição paradigmática do modo asilar para o modo psicossocial em saúde mental. Embora esta responsabilidade deva ser partilhada por todos os interessados (usuários, familiares, profissionais, governantes e sociedade em geral), cabe aos profissionais catalisar este processo.

Desta maneira, a conscientização do seu papel de profissional-cidadão é ponto de partida para motivar as ações desses profissionais na busca criativa de estratégias que envolvam a família no cotidiano do serviço e da comunidade no sentido de consolidar uma atenção em saúde mental digna para os usuários e seus familiares. Que os profissionais de saúde mental busquem construir junto com os usuários e familiares a compreensão de que outros espaços da comunidade podem servir de ambiente de promoção de saúde mental, ampliando as possibilidades de uma vida mais saudável em comunidade.

Embora haja imposições de interesses contrários aos da equipe de saúde mental do CAPS, a mobilização do meio social parece ser um espaço apropriado para as ações dessa equipe para a superação desse conflito. Neste contexto, a família tem se mostrado um locus fundamental e privilegiado para a construção coletiva em saúde mental.

A compreensão das experiências vividas dos familiares nos permite afirmar que a família é uma parceira imprescindível ao trabalho dos profissionais de saúde mental, destacando-se como um elemento importante para a consolidação de políticas públicas em saúde mental.

\section{REFERÊNCIAS}

1. Costa-Rosa A. 0 modo psicossocial: um paradigma das práticas substitutivas ao modo asilar. In: Amarante P, organizador. Ensaios: subjetividade, saúde mental, sociedade. Rio de Janeiro (RJ): Fiocruz; 2006. p.141-68.

2. Moreno V, Alencastre MB. A trajetória da família do portador de sofrimento psíquico. Rev Esc Enferm USP 2003 abr; 37(2): 43-50. 3. Amarante P. 0 homem e a serpente: outras histórias para a loucura e a psiquiatria. Rio de Janeiro (RJ): Fiocruz; 2003.

4. Ministério da Saúde (BR). Secretaria Executiva. Secretaria de Atenção à Saúde. Legislação em Saúde Mental: 1990-2004. 5ªd. Brasília (DF); 2004.

5. Ministério da Saúde (BR). Departamento de Ações Programáticas Estratégicas. Saúde mental no SUS: os centos de atenção psicossocial. Brasília (DF); 2004.

6. Schutz A. El problema de la realidad social. Natanson M, organizador. Buenos Aires (AR): Amorrortu; 2003.

7. Wagner HR, organizador. Fenomenologia e relações sociais: textos escolhidos de Alfred Schütz.. Rio de Janeiro (RJ): Zahar; 1979.

8. Schneider JF. Ser-família de esquizofrênico: o que é isto? Cascavel (PR): Edunioeste; 2001. 
9. Melman J. Família e doença mental: repensando a relação entre profissionais de saúde e família. São Paulo (SP): Escrituras; 2001.

10. Camatta MW, Nasi C, Schaurich D, Schneider JF. Contribuições da sociologia fenomenológica de Alfred Schütz para as pesquisas em enfermagem - revisão de literatura. Online Braz I Nurs [periódico oline]. 2008 ago; [citado ago 2008]; 7(2): [aprox. 10 telas]. Disponível em: http://www.uff.br/objnursing/index.php/nursing/article/view/ j.1676-4285.2008.1446/383.

11. Soares CB, Munari DB. Considerações acerca da sobrecarga em familiares de pessoas com transtornos mentais. Cienc Cuid Saude 2007 jul; 6(3): 357-62.

12. Mello R, Furegato ARF. Representações de usuários, familiares e profissionais acerca de um Centro de Atenção Psicossocial. Esc Anna Nery Rev Enferm 2008 jul; 12(3): 457-64.

13. Garcia MLP, Jorge MSB. Vivências de trabalhadores de um centro de atenção psicossocial: estudo à luz do pensamento de Martin
Heidegger e Hans-Georg Gadamer. Cienc Saude Colet 2006 jul; 11 (3): 763-74.

14. Schneider JF, Camatta MW, Nasi C. 0 trabalho em um centro de atenção psicossocial: uma análise sociológica fenomenológica em Alfred Schütz. Rev Gaucha Enferm 2007 out; 28(4): 520-26.

15. Pereira MAO, Bellizzoti RB. A consideração dos encargos familiares na busca da reabilitação psicossocial. Rev Gaucha Enferm 2004 jul; 25(3): 306-13.

16. Oliveira AGB. Trabalho e cuidado no contexto da atenção psicossocial: algumas reflexões. Esc Anna Nery Rev Enferm 2007 dez; 10(4): 694-702.

17. Wetzel C. Avaliação de serviço em saúde mental: a construção de um processo participativo [tese de doutorado]. Ribeirão Preto (SP): Escola de Enfermagem / USP; 2005. 